\title{
An asymmetric inhibition model of hemispheric differences in emotional processing
}

\author{
Gina M. Grimshaw ${ }^{1}{ }^{*}$ and David Carmel ${ }^{2}$ \\ 'School of Psychology, Victoria University of Wellington, Wellington, New Zealand \\ 2 Psychology Department, University of Edinburgh, Edinburgh, UK
}

Edited by:

Sebastian Ocklenburg, University of

Bergen, Norway

\section{Reviewed by:}

Luis J. Fuentes, Universidad de

Murcia, Spain

Wendy Heller, University of Illinois,

USA

\section{*Correspondence:}

Gina M. Grimshaw, School of

Psychology, Victoria University of

Wellington, Post Box 600, Wellington

6040, New Zealand

e-mail: gina.grimshaw@vuw.ac.nz

Two relatively independent lines of research have addressed the role of the prefrontal cortex in emotional processing. The first examines hemispheric asymmetries in frontal function; the second focuses on prefrontal interactions between cognition and emotion. We briefly review each perspective and highlight inconsistencies between them. We go on to describe an alternative model that integrates approaches by focusing on hemispheric asymmetry in inhibitory executive control processes. The asymmetric inhibition model proposes that right-lateralized executive control inhibits processing of positive or approach-related distractors, and left-lateralized control inhibits negative or withdrawal-related distractors. These complementary processes allow us to maintain and achieve current goals in the face of emotional distraction. We conclude with a research agenda that uses the model to generate novel experiments that will advance our understanding of both hemispheric asymmetries and cognition-emotion interactions.

Keywords: frontal asymmetry, hemispheric asymmetry, emotion, executive control, attention, EEG, prefrontal cortex, inhibition

HEMISPHERIC ASYMMETRIES IN EMOTIONAL PROCESSING Prefrontal cortex (PFC) plays a critical role in emotion, but we are just starting to understand how complex interactions within the PFC give rise to emotional experience. One productive line of research examines hemispheric differences in emotional processing, focusing primarily on electroencephalography (EEG) studies of individual differences in frontal asymmetry as indexed by alpha oscillations. Alpha power has long been assumed to be negatively correlated with cortical activity (Pfurtscheller et al., 1996; Klimesch, 1999; Coan and Allen, 2004); this has led to the convention of describing left and right frontal activity as inverse of left and right frontal alpha power. Commonly, frontal asymmetry is measured as a trait (usually in the resting state) and is associated with a number of clinical, personality, and emotional factors, sometimes collectively called affective style (Davidson, 1992, 1998; Wheeler et al., 1993). Relatively low left (compared to right) frontal activity is associated with withdrawalrelated traits including depression and anxiety (Thibodeau et al., 2006), shy temperament (Fox et al., 1995), dispositional negative affect (Tomarken and Davidson, 1994), and poor regulation of negative emotions (Jackson etal., 2003). In contrast, relatively low right (compared to left) frontal activity is associated with approach-related traits including dispositional positive affect (Tomarken and Davidson, 1994), trait anger (Harmon-Jones and Allen, 1998), sensation-seeking (Santesso et al., 2008), and high reward sensitivity (Harmon-Jones and Allen, 1997; Pizzagalli et al., 2005).

Frontal asymmetry does not, in general, correlate with current mood state, but with vulnerability or propensity to experience a particular state. For example, relatively low left frontal activity is observed in remitted depression (Henriques and Davidson, 1990; Gotlib et al., 1998), in the infants of depressed mothers (Field and
Diego, 2008), and in those with genetic or familial risk of the disorder (Bismark et al., 2010; Feng et al., 2012). It also predicts future depression in healthy individuals (Nusslock et al., 2011). The predictive strength of frontal asymmetry led Davidson (1992, 1998 ) to propose that it reflects a diathesis - a characteristic way of processing emotional information which, when combined with sufficient stress, leads to disorder.

Two models have tried to capture the fundamental difference between hemispheres. The valence hypothesis (Tomarken et al., 1992; Heller, 1993; Heller et al., 1998; Berntson et al., 2011) grounds emotional asymmetry in affect, and associates left frontal cortex with positive emotion and right frontal cortex with negative emotion. The alternative motivational direction hypothesis (Harmon-Jones and Allen, 1997; Sutton and Davidson, 1997; Harmon-Jones, 2003) grounds emotional asymmetry in action, and associates left frontal areas with motivation to approach, and right frontal areas with motivation to withdraw. These models have sparked decades of research and produced a catalog of traits, behaviors, and biomarkers that are correlated with different patterns of asymmetry (for reviews, see Coan and Allen, 2004; Harmon-Jones et al., 2010; Rutherford and Lindell, 2011).

We see two limitations with both models. The first is that they are premised on the assumption that there is a fundamental frontal asymmetry that should explain all findings. Given the diverse functions of prefrontal cortex and the complex nature of emotional processing, that assumption seems unlikely to hold (see also Miller etal., 2013). It is useful here to consider a potential analogy with language asymmetries, which exist at the levels of phonology, syntax, semantics, and prosody; each subserved by separate neural systems. Although there are overarching principles of hemispheric organization for language, 
the asymmetries themselves are at least partially dissociable. A second limitation is that both models are largely descriptive. Neither specifies the mechanisms that are lateralized, or explains how they give rise to either emotion or motivation. We again see precedent established in language research, where progress was made when researchers focused on hemispheric asymmetries in the component processes of language instead of global language function. In this perspective, we draw on emerging understanding of cognition-emotion interactions within prefrontal cortex to propose the asymmetric inhibition model, which focuses on asymmetries in executive control mechanisms that allow us to control our emotions so that we can meet current goals.

\section{COGNITION-EMOTION INTERACTIONS IN PREFRONTAL CORTEX}

The past decade has seen much progress in describing the complex interplay among brain networks that subserve emotion (for reviews, see Lindquist et al., 2012; Ochsner et al., 2012; Pessoa, 2013). To summarize, the generation of an emotional response begins with subcortical structures (including amygdala and ventral striatum) that are sensitive to the presence of behaviourally relevant stimuli. These structures modulate attention to the stimulus (Padmala et al., 2010; Pourtois et al., 2013), and activate a sequence of physiological responses that prepare us to approach or withdraw (Lang and Bradley, 2010). Orbito-frontal cortex (OFC) receives input from subcortical structures and sensory cortex, and computes emotional appraisal, tagging the stimulus as either punishment or reward in the context of one's current needs (Rolls, 2004; Kringelbach, 2005). Anterior insula (AI) integrates this information with afferent projections from the body, giving rise to emotional awareness or feeling (Craig, 2009; Gu et al., 2013). Ventro-medial PFC (vmPFC) is closely associated with emotional experience and evaluation of emotional relevance for the self (Ochsner et al., 2004).

Lateral regions of PFC, together with anterior cingulate cortex (ACC), have traditionally been linked to cognitive functions, but contemporary models include these as core aspects of emotional processing (Gray etal., 2002; Ochsner and Gross, 2005; Pessoa, 2008, 2013; Dolcos et al., 2011). Ventro-lateral regions (vlPFC) support response selection and inhibition, and are part of the bottom-up ventral attention network that orients attention to behaviourally-relevant (including emotional) stimuli (Corbetta and Shulman, 2002; Viviani, 2013). Dorso-lateral regions (dlPFC) are involved in processes that provide top-down cognitive control, including working memory and the executive functions of updating, shifting, and inhibition (Kane and Engle, 2002; Miyake and Friedman, 2012). They are also part of the top-down dorsal attention network that directs attention in goal-relevant ways (Corbetta and Shulman, 2002; Vossel et al., 2014). Both dlPFC and vlPFC are active during forms of emotion regulation that are cognitively mediated, including cognitive reappraisal (Ochsner et al., 2012), and attentional control over emotional distraction (Bishop et al., 2004; Hester and Garavan, 2009). Sometimes dorsal and ventral regions act reciprocally, reflecting a trade-off between the ventral emotion system and the dorsal executive system (Dolcos and McCarthy,
2006; Dolcos et al., 2011; Iordan etal., 2013). However, the regions sometimes act in concert, as during cognitive reappraisal (Ochsner et al., 2012) and attentional control (e.g., Bishop et al., 2004). The exact pattern of interaction may depend on task demands and the ways in which emotional distractors compete with goal-relevant information for executive control (Pessoa, 2013). Generally, increased activation in dlPFC is associated with decreased activation in amygdala and ventral striatum (Beauregard et al., 2001; Davidson, 2002; Bishop et al., 2004; Ochsner et al., 2012), although these regions are not directly connected (Ray and Zald, 2012). Rather, dlPFC likely achieves its regulatory effects either via connections to vlPFC (Wager et al., 2008), or indirectly through control of attentional and semantic processes (Banich, 2009; Banich et al., 2009) that alter how emotional stimuli are perceived and interpreted (Ochsner et al., 2012; Vossel et al., 2014).

Hemispheric asymmetry does not figure prominently in current theories of prefrontal function in emotion. One reason might be methodological; most data come from fMRI studies that are rarely designed to assess asymmetry. When asymmetries are reported, they are often incidental to the experimental design and based on findings of significant activation in one hemisphere but not the other. However, to determine if the hemispheres differ from each other it is necessary to directly compare activation in homologous regions (Jansen et al., 2006). Such analyzes are common in studies of language asymmetries (e.g., Jansen et al., 2006; Cai et al., 2013), but rare in studies of emotion. A second issue is that there are far more studies of negative than positive emotional processing, meaning that meta-analyzes are dominated by negative studies (e.g., Phan et al., 2002; Wager et al., 2003; Ochsner et al., 2012) and individual studies rarely include both positive and negative stimuli. Unless both valences are represented, it is impossible to determine whether any observed hemispheric differences are related to valence or to emotional processes more generally.

Even given these caveats, there is little compelling evidence for asymmetries related to the generation of emotional experience. Amygdala activity is asymmetric; however, the asymmetry is related to stimulus properties, with the left more active for verbal and the right for visual representations (Costafreda et al., 2008; McMenamin and Marsolek, 2013). OFC is organized along a lateral gradient, with rewards represented in medial areas and punishers in lateral areas (Kringelbach, 2005), but again with no reliable hemispheric asymmetries related to either valence or motivational direction. Studies in which emotions are induced show bilateral activation of medial PFC regardless of valence (Phan et al., 2002; Wager et al., 2003). Multivoxel pattern analysis (e.g., Kassam et al., 2013; Kragel and LaBar, 2014), shows that there are distinct patterns of activity associated with positive and negative emotional experience, but these are broadly and bilaterally distributed across ventro-medial and orbito-frontal regions. There is, however, some evidence for asymmetries in the cognitive control of emotion associated with lateral PFC (Wager et al., 2003; Ochsner et al., 2012). We return to this below.

\section{THE ASYMMETRIC INHIBITION MODEL}

The absence of consistent asymmetries in fMRI studies stands in contrast to robust findings of emotion-related asymmetries 
in EEG studies. How can we reconcile these findings? We start with an important observation - that EEG asymmetries are seen in alpha power. The assumption underlying all EEG asymmetry research is that alpha is inversely correlated with cortical activity. Therefore, asymmetric alpha levels are taken to reflect greater cortical activity in the hemisphere with lower alpha (Coan and Allen, 2004). This assumption is overly simplistic and does not reflect current knowledge of either the differentiation of prefrontal networks or the functional role of alpha oscillations. Few studies of EEG asymmetry use source localisation procedures, but those that have done so localize alpha asymmetries to dlPFC (Pizzagalli et al., 2005; Koslov et al., 2011). More generally, studies that measure simultaneous EEG and resting state fMRI find alpha to be inversely correlated with activity in the dorsal fronto-parietal network that coordinates activity between dlPFC and posterior parietal cortex (Laufs et al., 2003; Mantini et al., 2007) and plays an important role in the top-down executive control of attention (Corbetta and Shulman, 2002), primarily through modulations of sensory processing (for review, see Vossel et al., 2014). Functionally, alpha oscillations play a key role in attentional control and gating of perceptual awareness (Hanslmayr et al., 2011; Mazaheri et al., 2013).

The strong association between alpha and the fronto-parietal network leads us to propose that EEG asymmetries reflect the integrity of executive control mechanisms that inhibit interference from irrelevant emotional distractors. Executive control holds goal-relevant information in working memory in order to prioritize attention to relevant (over irrelevant) information (Desimone and Duncan, 1995; Kane and Engle, 2002; Lavie, 2005). Emotional stimuli are strong competitors for processing resources - this is adaptive, because they have such high behavioral relevance. But sometimes success depends on our ability to ignore the emotional stimulus and get on with the task at hand. With the Asymmetric Inhibition Model, we propose that mechanisms in left dlPFC inhibit negative distractors, and those in right dlPFC inhibit positive distractors. As we detail below, the model both accounts for much existing data and yields specific, testable predictions about how manipulations of executive control should affect hemispheric asymmetry.

\section{EXISTING EVIDENCE FOR THE MODEL}

Our goal here is not to systematically review all research on emotional asymmetry (see comprehensive reviews by Coan and Allen, 2004; Harmon-Jones et al., 2010; Rutherford and Lindell, 2011). Rather, we provide examples to demonstrate that many existing asymmetries can be interpreted in terms of executive control. In the clinical literature, for example, trait EEG asymmetries predict vulnerability to several emotional disorders that are also characterized by difficulties with executive control. Those that are associated with relatively low left frontal activity (such as depression and anxious arousal) entail difficulty in disengaging attention from negative information (Eysenck et al., 2007; Cisler and Koster, 2010; De Raedt and Koster, 2010; Gotlib and Joormann, 2010). Poor selfregulation and addiction, both associated with relatively low right frontal activity, entail difficulty in inhibiting positive distractions (Bechara, 2005; Garavan and Hester, 2007; Goldstein and Volkow, 2011).
In experimental contexts, the model predicts that EEG asymmetries should be correlated with ability to control emotional distractions. Although most EEG studies focus on personality traits or emotional responses, a few recent studies have tested relationships between trait asymmetry and attention. In all studies, emotional faces were used as cues, but the facial expressions themselves were task-irrelevant. In a spatial cueing task, people with low left frontal activity showed difficulty disengaging from angry (but not happy) faces (Miskovic and Schmidt, 2010). In our own lab (Grimshaw et al., under review) we found similar results using a dot-probe task, which can be used to indicate the capture of attention by an emotional stimulus. Participants with low left frontal activity had difficulty shifting attention away from angry (but not happy) faces, but those with high left frontal activity were unaffected by the faces. Pérez-Edgar et al. (2013) had participants perform the same dot-probe task after an emotional stressor. Those who responded to the stress by increasing left frontal activity showed no attentional biases in the dot-probe task, but those who failed to do so showed biases to angry (but not happy) faces. All these studies are consistent with the idea that left frontal activity, as measured in EEG, reflects of the ability to recruit executive control processes that inhibit negative distractions when they are contrary to current goals.

Neuroimaging studies provide some evidence consistent with the model, if we are mindful of the caveats identified in Section "Cognition-Emotion Interactions in Prefrontal Cortex". We focus on studies in which the emotional stimulus or dimension is taskirrelevent and must be ignored (e.g., emotional Stroop, irrelevant emotional flankers). These tasks consistently produce greater activation for emotional than neutral distractors in dlPFC, and often in vlPFC. Compton etal. (2003) found increased activation in left dlPFC during presentation of negative words in an emotional Stroop task. Failure to recruit left dlPFC in the face of negative distraction has been associated with depression (Engels et al., 2010; Herrington et al., 2010), anxiety (Bishop et al., 2004), trait negative affect (Crocker et al., 2012) and schizotypy (Mohanty et al., 2005). Positive stimuli (including erotica, foods, and addictionrelated cues) can also tax executive control processes (Pourtois et al., 2013). Control over positive distractions is commonly associated with activity in right vlPFC (Beauregard et al., 2001; Hester and Garavan, 2009; Meyer et al., 2011) and sometimes in right dlPFC (Beauregard et al., 2001).

Across these EEG and neuroimaging studies, there is stronger support for left lateralization in the inhibition of negative stimuli than right lateralization in the inhibition of positive stimuli, even in studies that used both positive and negative stimuli (e.g., Compton et al., 2003; Pérez-Edgar et al., 2013). This is problematic for our model, because support depends critically on the hemisphere by valence interaction. One possible explanation for this imbalance is that most studies of emotional distraction have used emotional faces or words as stimuli. Although these stimuli can be matched on subjective ratings of arousal, negative words and faces typically produce more behavioral interference than positive stimuli (Pratto and John, 1991; Horstmann etal., 2006), suggesting that they are more taxing for executive control systems. A better test of the model would use positive and negative stimuli such as pictures of scenes, 
which have equivalent potential to attract and hold attention (e.g., Schimmack, 2005; Vogt et al., 2008). Consistent with this speculation, the studies that associate inhibition of positive distraction with right lateral PFC all use emotional pictures as stimuli.

As correlational methods, EEG and fMRI cannot establish causal relationships between neural activity and function. However, brain stimulation methods, including transcranial magnetic stimuluation (TMS) and transcranial direct current stimulation (tDCS) can directly alter neural function and so establish causality. In clinical research, activation of left dlPFC with both TMS and tDCS is effective in the treatment of depression (Kalu et al., 2012). Consistent with the asymmetric inhibition model, treatment appears not to alter mood directly, but to improve executive control so that patients are better able to control negative biases (Moser et al., 2002). Conversely, right-sided stimulation affects motivation to approach positive stimuli. For example, activation of right dlPFC leads to reductions in both craving (Boggio et al., 2008; Fregni et al., 2008) and risky decision-making (Fecteau et al., 2007).

\section{AN AGENDA FOR FUTURE RESEARCH}

We are not the first to suggest that emotional asymmetries reflect inhibitory processes (see Terzian, 1964; Jackson et al., 2003; Davidson, 2004; Coan et al., 2006, for explicit statements about asymmetries in inhibitory or regulatory functions). We extend this tradition by specifying a neurologically and cognitively plausible mechanism through which hemispheric differences in emotional processing might emerge. The asymmetric inhibition model draws on our increasingly sophisticated understanding of prefrontal function. In doing so, it not only provides explanation of many existing findings, but also suggests new experimental approaches that will move our conceptualization of emotional asymmetry beyond its current descriptive level.

The model argues for a shift in focus from the study of emotion per se toward the study of executive processes that are subserved by lateral PFC and the dorsal fronto-parietal network. Experiments should draw on the rich literature in cognitive psychology that has identified ways to target specific components of executive control. A simple but useful paradigm involves use of irrelevant distractors (e.g., Forster and Lavie, 2008). The "goal" is an emotionally neutral task, such as finding a target letter in a display that is flanked by irrelevant distractor images, which can be either emotional or neutral. One can then manipulate the availability of executive control in order to assess its role in inhibition. For example, increasing working memory load decreases the availability of executive control and its ability to inhibit irrelevant distractors (Lavie etal., 2004; Hester and Garavan, 2005; Carmel et al., 2012). Conversely, motivational manipulations enhance relevance of the goal and increase ability to inhibit distractors (Pessoa, 2009; Hu et al., 2013). These paradigms can be used in combination with fMRI and EEG recordings to determine whether positive and negative distractions are controlled by dissociable mechanisms, and whether those are differentially lateralized.

Because of inherent limitations in EEG and fMRI approaches, stimulation studies using TMS and tDCS are important for establishing causal relationships between prefrontal function and emotional inhibition. Brain stimulation may be particularly useful in hemispheric asymmetry studies, because it provides access to higher order frontal processes that are not as amenable to experimental manipulations (such as lateralized perceptual input) that have been used to study asymmetries in other domains. The asymmetric inhibition model makes specific predictions about the effects of lateralized stimulation on inhibition. Activation of left dlPFC should improve ability to inhibit negative (but not positive) distractions; activation of right dlPFC should improve ability to inhibit positive (but not negative) distractions.

The asymmetric inhibition model differs from other accounts of emotional asymmetry in two ways. First, it does not associate an entire hemisphere with a specific emotional or motivational state; rather it focuses on one asymmetry in a single mechanism, allowing it to generate specific and testable predictions. Second, the model turns conventional wisdom on its head; associating left PFC with the inhibition of withdrawal (instead of the support of approach), and right PFC with the inhibition of approach (instead of the support of withdrawal). The model is therefore consistent with current work on cognitionemotion interactions that emphasizes the role of lateral PFC in inhibitory executive control. Although we have shown here the value of incorporating cognition-emotion interactions into models of hemispheric asymmetry, we also think that models of cognition-emotion interaction would benefit from more careful consideration of hemispheric differences. Integration of perspectives should yield richer understanding of emotional processes.

\section{ACKNOWLEDGMENTS}

Our research was supported by a grant from the Royal Society of New Zealand Marsden Fund. We thank Laura Kranz for assistance with manuscript preparation.

\section{REFERENCES}

Banich, M. T. (2009). Executive function: the search for an integrated account. Curr. Dir. Psychol. Sci. 18, 89-94. doi: 10.1111/j.1467-8721.2009.01615.x

Banich, M. T., Mackiewicz, K. L., Depue, B. E., Whitmer, A., Miller, G. A., and Heller, W. (2009). Cognitive control mechanisms, emotion, and memory: a neural perspective with implications for psychopathology. Neurosci. Biobehav. Rev. 33, 613-630. doi: 10.1016/j.neubiorev.2008.09.010

Beauregard, M., Levesque, J., and Bourgouin, P. (2001). Neural correlates of conscious self-regulation of emotion. J. Neurosci. 21, RC165.

Bechara, A. (2005). Decision making, impulse control and loss of willpower to resist drugs: a neurocognitive perspective. Nat. Neurosci. 8, 1458-1463. doi: $10.1038 / \mathrm{nn} 1584$

Berntson, G. G., Norman, G. J., and Cacioppo, J. T. (2011). Comment: laterality and evaluative bivalence: a neuroevolutionary perspective. Emot. Rev. 3, 344-346. doi: 10.1177/1754073911402401

Bishop, S., Duncan, J., Brett, M., and Lawrence, A. D. (2004). Prefrontal cortical function and anxiety: controlling attention to threat-related stimuli. Nat. Neurosci. 7, 184-188. doi: 10.1038/nn1173

Bismark, A. W., Moreno, F. A., Stewart, J. L., Towers, D. N., Coan, J. A., Oas, J., et al. (2010). Polymorphisms of the HTRla allele are linked to frontal brain electrical asymmetry. Biol. Psychol. 83, 153-158. doi: 10.1016/j.biopsycho.2009. 12.002

Boggio, P. S., Sultani, N., Fecteau, S., Merabet, L., Mecca, T., Pascual-Leone, A., et al. (2008). Prefrontal cortex modulation using transcranial DC stimulation reduces alcohol craving: a double-blind, sham-controlled study. Drug Alcohol Depend. 92, 55-60. doi: 10.1016/j.drugalcdep.2007.06.011 
Cai, Q., Van der Haegen, L., and Brysbaert, M. (2013). Complementary hemispheric specialization for language production and visuospatial attention. Proc. Natl. Acad. Sci. U.S.A. 110, E322-E330. doi: 10.1073/pnas.1212956110

Carmel, D., Fairnie, J., and Lavie, N. (2012). Weight and see: loading working memory improves incidental identification of irrelevant faces. Front. Psychol. 3:286. doi: 10.3389/fpsyg.2012.00286

Cisler, J. M., and Koster, E. H. W. (2010). Mechanisms of attentional biases toward threat in anxiety disorders: an integrative review. Clin. Psychol. Rev. 30, 203-216. doi: 10.1016/j.cpr.2009.11.003

Coan, J. A., and Allen, J. J. (2004). Frontal EEG asymmetry as a moderator and mediator of emotion. Biol. Psychol. 67, 7-49. doi: 10.1016/j.biopsycho.2004. 03.002

Coan, J. A., Allen, J. J. B., and McKnight, P. E. (2006). A capability model of individual differences in frontal EEG asymmetry. Biol. Psychol. 72, 198-207. doi: 10.1016/j.biopsycho.2005.10.003

Compton, R. J., Banich, M. T., Mohanty, A., Milham, M. P., Herrington, J., Miller G. A., et al. (2003). Paying attention to emotion: an fMRI investigation of cognitive and emotional stroop tasks. Cogn. Affect. Behav. Neurosci. 3, 81-96. doi: 10.3758/CABN.3.2.81

Corbetta, M., and Shulman, G. L. (2002). Control of goal-directed and stimulusdriven attention in the brain. Nat. Rev. Neurosci. 3, 201-215. doi: 10.1038/ nrn755

Costafreda, S. G., Brammer, M. J., David, A. S., and Fu, C. H. Y. (2008). Predictors of amygdala activation during the processing of 385 PET and fMRI studies. Brain Res. Rev. 58, 57-70. doi: 10.1016/j.brainresrev.2007.10.012

Craig, A. D. (2009). Emotional moments across time: a possible neural basis for time perception in the anterior insula. Philo. Trans. R. Soc. B Biol. Sci. 364, 1933-1942. doi: 10.1098/rstb.2009.0008

Crocker, L. D., Heller, W., Spielberg, J. M., Warren, S. L., Bredemeier, K., Sutton, B. P., et al. (2012). Neural mechanisms of attentional control differentiate trait and state negative affect. Front. Psychol. 3:298. doi: 10.3389/fpsyg.2012.00298

Davidson, R. J. (1992). Anterior cerebral asymmetry and the nature of emotion. Brain Cogn. 20, 125-151. doi: 10.1016/0278-2626(92)90065-T

Davidson, R. J. (1998). Affective style and affective disorders: perspectives from affective neuroscience. Cogn. Emot. 12, 307-330. doi: 10.1080/0269993983 79628

Davidson, R. J. (2002). Anxiety and affective style: role of prefrontal cortex and amygdala. Biol. Psychiatry 51, 68-80. doi: 10.1016/S0006-3223(01)01328-2

Davidson, R. J. (2004). What does the prefrontal cortex "do" in affect: perspectives on frontal EEG asymmetry research. Biol. Psychol. 67, 219-233. doi: 10.1016/j.biopsycho.2004.03.008

De Raedt, R., and Koster, E. H. W. (2010). Understanding vulnerability for depression from a cognitive neuroscience perspective: a reappraisal of attentional factors and a new conceptual framework. Cogn. Affect. Behav. Neurosci. 10, 50-70. doi 10.3758/CABN.10.1.50

Desimone, R., and Duncan, J. (1995). Neural mechanisms of selective visual attention. Annu. Rev. Neurosci. 18, 193-222. doi 10.1146/annurev.ne.18.030195.001205

Dolcos, F., Iordan, A. D., and Dolcos, S. (2011). Neural correlates of emotioncognition interactions: a review of evidence from brain imaging investigations. $J$. Cogn. Psychol. 23, 669-694. doi: 10.1080/20445911.2011.594433

Dolcos, F., and McCarthy, G. (2006). Brain systems mediating cognitive interference by emotional distraction. J. Neurosci. 26, 2072-2079. doi: 10.1523/JNEUROSCI.5042-05.2006

Engels, A. S., Heller, W., Spielberg, J. M., Warren, S. L., Sutton, B. P., Banich, M. T., et al. (2010). Co-occurring anxiety influences patterns of brain activity in depression. Cogn. Affect. Behav. Neurosci. 10, 141-156. doi: 10.3758/CABN.10.1.141

Eysenck, M. W., Derakshan, N., Santos, R., and Calvo, M. G. (2007). Anxiety and cognitive performance: attentional control theory. Emotion 7, 336-353. doi: 10.1037/1528-3542.7.2.336

Fecteau, S., Knoch, D., Fregni, F., Sultani, N., Boggio, P., and Pascual-Leone, A. (2007). Diminishing risk-taking behavior by modulating activity in the prefrontal cortex: a direct current stimulation study. J. Neurosci. 27, 12500-12505. doi: 10.1523/JNEUROSCI.3283-07.2007

Feng, X., Forbes, E. E., Kovacs, M., George, C. J., Lopez-Duran, N. L., Fox, N. A., et al. (2012). Children's depressive symptoms in relation to EEG frontal asymmetry and maternal depression. J. Abnorm. Child Psychol. 40, 265-276. doi: 10.1007/s10802011-9564-9
Field, T., and Diego, M. (2008). Maternal depression effects on infant frontal EEG asymmetry. Int. J. Neurosci. 118, 1081-1108. doi: 10.1080/00207450701 769067

Forster, S., and Lavie, N. (2008). Attentional capture by entirely irrelevant distractors. Vis. Cogn. 16, 200-214. doi: 10.1080/13506280701465049

Fox, N. A., Rubin, K. H., Calkins, S. D., Marshall, T. R., Coplan, R. J., Porges, S. W., et al. (1995). Frontal activation asymmetry and social competence at four years of age. Child Dev. 66, 1770-1784. doi: 10.2307/1131909

Fregni, F., Orsati, F., Pedrosa, W., Fecteau, S., Tome, F. A., Nitsche, M. A., et al. (2008). Transcranial direct current stimulation of the prefrontal cortex modulates the desire for specific foods. Appetite 51, 34-41. doi: 10.1016/j.appet.2007. 09.016

Garavan, H., and Hester, R. (2007). The role of cognitive control in cocaine dependence. Neuropsychol. Rev. 17, 337-345. doi: 10.1007/s11065-007-9034-x

Goldstein, R. Z., and Volkow, N. D. (2011). Dysfunction of the prefrontal cortex in addiction: neuroimaging findings and clinical implications. Nat. Rev. Neurosci. 12, 652-669. doi: 10.1038/nrn3119

Gotlib, I. H., and Joormann, J. (2010). Cognition and depression: current status and future directions. Annu. Rev. Clin. Psychol. 6, 285-312. doi: 10.1146/annurev.clinpsy.121208.131305

Gotlib, I. H., Ranganath, C., and Rosenfeld, J. P. (1998). Frontal EEG alpha asymmetry, depression, and cognitive functioning. Cogn. Emot. 12, 449-478. doi: 10.1080/026999398379673

Gray, J. R., Braver, T. S., and Raichle, M. E. (2002). Integration of emotion and cognition in the lateral prefrontal cortex. Proc. Natl. Acad. Sci. U.S.A. 99, 41154120. doi: 10.1073/pnas.062381899

Gu, X., Hof, P. R., Friston, K. J., and Fan, J. (2013). Anterior insular cortex and emotional awareness. J. Comp. Neurol. 521, 3371-3388. doi: 10.1002/cne.23368

Hanslmayr, S., Gross, J., Klimesch, W., and Shapiro, K. L. (2011). The role of alpha oscillations in temporal attention. Brain Res. Rev. 67, 331-343. doi: 10.1016/j.brainresrev.2011.04.002

Harmon-Jones, E. (2003). Clarifying the emotive functions of asymmetrical frontal cortical activity. Psychophysiology 40, 838-848. doi: 10.1111/1469-8986.00121

Harmon-Jones, E., and Allen, J. J. (1997). Behavioral activation sensitivity and resting frontal EEG asymmetry: covariation of putative indicators related to risk for mood disorders. J. Abnorm. Psychol. 106, 159-163. doi: 10.1037/0021843X.106.1.159

Harmon-Jones, E., and Allen, J. J. (1998). Anger and frontal brain activity: EEG asymmetry consistent with approach motivation despite negative affective valence. J. Pers. Soc. Psychol. 74, 1310-1316. doi: 10.1037/0022-3514.74. 5.1310

Harmon-Jones, E., Gable, P. A., and Peterson, C. K. (2010). The role of asymmetric frontal cortical activity in emotion-related phenomena: a review and update. Biol. Psychol. 84, 451-462. doi: 10.1016/j.biopsycho.2009.08.010

Heller, W. (1993). Neuropsychological mechanisms of individual differences in emotion, personality, and arousal. Neuropsychology 7, 476-489. doi: 10.1037/0894-4105.7.4.476

Heller, W., Nitschke, J. B., and Miller, G. A. (1998). Lateralization in emotion and emotional disorders. Curr. Dir. Psychol. Sci. 7, 26-32. doi: 10.1111/14678721.ep11521823

Henriques, J. B., and Davidson, R. J. (1990). Regional brain electrical asymmetries discriminate between previously depressed and healthy control subjects. $J$. Abnorm. Psychol. 99, 22-31. doi: 10.1037/0021-843X.99.1.22

Herrington, J. D., Heller, W., Mohanty, A., Engels, A. S., Banich, M. T., Webb, A. G., et al. (2010). Localization of asymmetric brain function in emotion and depression. Psychophysiology 47, 442-454. doi: 10.1111/j.1469-8986.2009.00958.x

Hester, R., and Garavan, H. (2005). Working memory and executive function: the influence of content and load on the control of attention. Mem. Cognit. 33, 221-233. doi: 10.3758/BF03195311

Hester, R., and Garavan, H. (2009). Neural mechanisms underlying drug-related cue distraction in active cocaine users. Pharmacol. Biochem. Behav. 93, 270-277. doi: 10.1016/j.pbb.2008.12.009

Horstmann, G., Scharlau, I., and Ansorge, U. (2006). More efficient rejection of happy than of angry face distractors in visual search. Psychon. Bull. Rev. 13, 1067-1073. doi: 10.3758/BF03213927

Hu, K., Padmala, S., and Pessoa, L. (2013). Interactions between reward and threat during visual processing. Neuropsychologia 51, 1763-1772. doi: 10.1016/j.neuropsychologia.2013.05.025 
Iordan, A. D., Dolcos, S., and Dolcos, F. (2013). Neural signatures of the response to emotional distraction: a review of evidence from brain imaging investigations. Front. Hum. Neurosci. 7:200. doi: 10.3389/fnhum.2013.00200

Jackson, D. C., Mueller, C. J., Dolski, I., Dalton, K. M., Nitschke, J. B., Urry, H. L., et al. (2003). Now you feel it, now you don't frontal brain electrical asymmetry and individual differences in emotion regulation. Psychol. Sci. 14, 612-617. doi: 10.1046/j.0956-7976.2003.psci3_1473.x

Jansen, A., Menke, R., Sommer, J., Förster, A. F., Bruchmann, S., Hempleman, J., et al. (2006). The assessment of hemispheric lateralization in functional MRI-robustness and reproducibility. Neuroimage 33, 204-217. doi: 10.1016/j.neuroimage.2006.06.019

Kalu, U. G., Sexton, C. E., Loo, C. K., and Ebmeier, K. P. (2012). Transcranial direct current stimulation in the treatment of major depression: a meta-analysis. Psychol. Med. 42, 1791-1800. doi: 10.1017/S0033291711003059

Kane, M. J., and Engle, R. W. (2002). The role of prefrontal cortex in working-memory capacity, executive attention, and general fluid intelligence: an individual-differences perspective. Psychon. Bull. Rev. 9, 637-671. doi 10.3758/BF03196323

Kassam, K. S., Markey, A. R., Cherkassky, V. L., Loewenstein, G., and Just, M A. (2013). Identifying emotions on the basis of neural activation. PLoS ONE 8:e66032. doi: 10.1371/journal.pone.0066032

Klimesch, W. (1999). EEG alpha and theta oscillations reflect cognitive and memory performance: a review and analysis. Brain Res. Rev. 29, 169-195. doi: 10.1016/S0165-0173(98)00056-3

Koslov, K., Mendes, W. B., Pajtas, P. E., and Pizzagalli, D. A. (2011). Asymmetry in resting intracortical activity as a buffer to social threat. Psychol. Sci. 22, 641-649. doi: $10.1177 / 0956797611403156$

Kragel, P. A., and LaBar, K. S. (2014). Advancing emotion theory with multivariate pattern classification. Emot. Rev. 6, 160-174. doi: 10.1177/1754073913512519

Kringelbach, M. L. (2005). The human orbitofrontal cortex: linking reward to hedonic experience. Nat. Rev. Neurosci. 6, 691-702. doi: 10.1038/nrn1747

Lang, P. J., and Bradley, M. M. (2010). Emotion and the motivational brain. Biol. Psychol. 84, 437-450. doi: 10.1016/j.biopsycho.2009.10.007

Laufs, H., Kleinschmidt, A., Beyerle, A., Eger, E., Salek-Haddadi, A., Preibisch, C., et al. (2003). EEG-correlated fMRI of human alpha activity. Neuroimage 19 1463-1476. doi: 10.1016/S1053-8119(03)00286-6

Lavie, N. (2005). Distracted and confused?: selective attention under load. Trends Cogn. Sci. 9, 75-82. doi: 10.1016/j.tics.2004.12.004

Lavie, N., Hirst, A., de Fockert, J. W., and Viding, E. (2004). Load theory of selective attention and cognitive control. J. Exp. Psychol. Gen. 133, 339-354. doi: 10.1037/0096-3445.133.3.339

Lindquist, K. A., Wager, T. D., Kober, H., Bliss-Moreau, E., and Barrett, L. F. (2012). The brain basis of emotion: a meta-analytic review. Behav. Brain Sci. 35, 121-143. doi: 10.1017/S0140525X11000446

Mantini, D., Perrucci, M. G., Del Gratta, C., Romani, G. L., and Corbetta, M. (2007) Electrophysiological signatures of resting state networks in the human brain. Proc Natl. Acad. Sci. U.S.A. 104, 13170-13175. doi: 10.1073/pnas.0700668104

Mazaheri, A., van Schouwenburg, M., Dimitrijevic, A., Denys, D., Cools, R., and Jensen, O. (2013). Region specific modulations in oscillatory alpha activity serves to facilitate processing in the visual and auditory modalities. Neuroimage 87, 356-362. doi: 10.1016/j.neuroimage.2013.10.052

McMenamin, B. W., and Marsolek, C. J. (2013). Can theories of visual representation help to explain asymmetries in amygdala function? Cogn. Affect. Behav. Neurosci. 13, 211-224. doi: 10.3758/s13415-012-0139-1

Meyer, M. L., Berkman, E. T., Karremans, J. C., and Lieberman, M. D. (2011) Incidental regulation of attraction: the neural basis of the derogation of attractive alternatives in romantic relationships. Cogn. Emot. 25, 490-505. doi 10.1080/02699931.2010.527494

Miller, G. A., Crocker, L. D., Spielberg, J. M., Infantolino, Z. P., and Heller, W. (2013). Issues in localization of brain function: the case of lateralized frontal cortex in cognition, emotion, and psychopathology. Front. Integr. Neurosci. 7:2. doi: 10.3389/fnint.2013.00002

Miskovic, V., and Schmidt, L. A. (2010). Frontal brain electrical asymmetry and cardiac vagal tone predict biased attention to social threat. Int. J. Psychophysiol 75, 332-338. doi: 10.1016/j.ijpsycho.2009.12.015

Miyake, A., and Friedman, N. P. (2012). Nature and organization of individual differences in executive functions: four general conclusions. Curr. Dir. Psychol. Sci. 21, 8-14. doi: 10.1177/0963721411429458
Mohanty, A., Herrington, J. D., Koven, N. S., Fisher, J. E., Wenzel, E. A., Webb, A. G., etal. (2005). Neural mechanisms of affective interference in schizotypy. J. Abnorm. Psychol. 114, 16-27. doi: 10.1037/0021-843X. 114.1.16

Moser, D. J., Jorge, R. E., Manes, F., Paradiso, S., Benjamin, M. L., and Robinson, R. G. (2002). Improved executive functioning following repetitive transcranial magnetic stimulation. Neurology 58, 1288-1290. doi: 10.1212/WNL.58. 8.1288

Nusslock, R., Shackman, A. J., Harmon-Jones, E., Alloy, L. B., Coan, J. A., and Abramson, L. Y. (2011). Cognitive vulnerability and frontal brain asymmetry: common predictors of first prospective depressive episode. J. Abnorm. Psychol. 120, 497-503. doi: 10.1037/a0022940

Ochsner, K. N., and Gross, J. J. (2005). The cognitive control of emotion. Trends Cogn. Sci. 9, 242-249. doi: 10.1016/j.tics.2005.03.010

Ochsner, K. N., Knierim, K., Ludlow, D. H., Hanelin, J., Ramachandran, T., Glover, G., et al. (2004). Reflecting upon feelings: an fMRI study of neural systems supporting the attribution of emotion to self and other. J. Cogn. Neurosci. 16, 1746-1772. doi: 10.1162/0898929042947829

Ochsner, K. N., Silvers, J. A., and Buhle, J. T. (2012). Functional imaging studies of emotion regulation: a synthetic review and evolving model of the cognitive control of emotion. Ann. N. Y. Acad. Sci. 1251, E1-E24. doi: 10.1111/j.17496632.2012.06751.x

Padmala, S., Lim, S. L., and Pessoa, L. (2010). Pulvinar and affective significance: responses track moment-to-moment stimulus visibility. Front. Hum. Neurosci. 4:64. doi: 10.3389/fnhum.2010.00064

Pérez-Edgar, K., Kujawa, A., Nelson, S. K., Cole, C., and Zapp, D. J. (2013). The relation between electroencephalogram asymmetry and attention biases to threat at baseline and under stress. Brain Cogn. 82, 337-343. doi: 10.1016/j.bandc.2013.05.009

Pessoa, L. (2008). On the relationship between emotion and cognition. Nat. Rev. Neurosci. 9, 148-158. doi: 10.1038/nrn2317

Pessoa, L. (2009). How do emotion and motivation direct executive control? Trends Cogn. Sci. 13, 160-166. doi: 10.1016/j.tics.2009.01.006

Pessoa, L. (2013). The Cognitive-Emotional Brain: From Interactions to Integration. Cambridge: MIT Press.

Pfurtscheller, G., Stancak, A. Jr., and Neuper, C. (1996). Event-related synchronization (ERS) in the alpha band-an electrophysiological correlate of cortical idling: a review. Int. J. Psychophysiol. 24, 39-46. doi: 10.1016/S0167-8760(96) 00066-9

Phan, K. L., Wager, T., Taylor, S. F., and Liberzon, I. (2002). Functional neuroanatomy of emotion: a meta-analysis of emotion activation studies in PET and fMRI. Neuroimage 16, 331-348. doi: 10.1006/nimg.2002.1087

Pizzagalli, D. A., Sherwood, R. J., Henriques, J. B., and Davidson, R. J. (2005). Frontal brain asymmetry and reward responsiveness: a source-localization study. Psychol. Sci. 16, 805-813. doi: 10.1111/j.1467-9280.2005.01618.x

Pourtois, G., Schettino, A., and Vuilleumier, P. (2013). Brain mechanisms for emotional influences on perception and attention: what is magic and what is not. Biol. Psychol. 92, 492-512. doi: 10.1016/j.biopsycho.2012.02.007

Pratto, F., and John, O. P. (1991). Automatic vigilance: the attention-grabbing power of negative social information. J. Pers. Soc. Psychol. 61, 380-391. doi: 10.1037/0022-3514.61.3.380

Ray, R. D., and Zald, D. H. (2012). Anatomical insights into the interaction of emotion and cognition in the prefrontal cortex. Neurosci. Biobehav. Rev. 36, 479-501. doi: 10.1016/j.neubiorev.2011.08.005

Rolls, E. T. (2004). The functions of the orbitofrontal cortex. Brain Cogn. 55, 11-29. doi: 10.1016/S0278-2626(03)00277-X

Rutherford, H. J. V., and Lindell, A. K. (2011). Thriving and surviving: approach and avoidance motivation and lateralization. Emot. Rev. 3, 333-343. doi: $10.1177 / 1754073911402392$

Santesso, D. L., Segalowitz, S. J., Ashbaugh, A. R., Antony, M. M., McCabe, R. E., and Schmidt, L. A. (2008). Frontal EEG asymmetry and sensation seeking in young adults. Biol. Psychol. 78, 164-172. doi: 10.1016/j.biopsycho.2008.02.003

Schimmack, U. (2005). Attentional interference effects of emotional pictures: threat, negativity, or arousal. Emotion 5, 55-66. doi: 10.1037/1528-3542. 5.1 .55

Sutton, S. K., and Davidson, R. J. (1997). Prefrontal brain asymmetry: a biological substrate of the behavioral approach and inhibition systems. Psychol. Sci. 8, 204210. doi: 10.1111/j.1467-9280.1997.tb00413.x 
Terzian, H. (1964). Behavioural and EEG effects of intracarotid sodium amytal injection. Acta Neurochir. 12, 230-239. doi: 10.1007/BF01 402095

Thibodeau, R., Jorgensen, R. S., and Kim, S. (2006). Depression, anxiety, and resting frontal EEG asymmetry: a meta-analytic review. J. Abnorm. Psychol. 115, 715-729. doi: 10.1037/0021-843X.115.4.715

Tomarken, A. J., and Davidson, R. J. (1994). Frontal brain activation in repressors and nonrepressors. J. Abnorm. Psychol. 103, 339-349. doi: 10.1037/0021843X.103.2.339

Tomarken, A. J., Davidson, R. J., Wheeler, R. E., and Doss, R. C. (1992). Individual differences in anterior brain asymmetry and fundamental dimensions of emotion. J. Pers. Soc. Psychol. 62, 676-687. doi: 10.1037/0022-3514. 62.4 .676

Viviani, R. (2013). Emotion regulation, attention to emotion, and the ventral attentional network. Front. Hum. Neurosci. 7:746. doi: 10.3389/fnhum.2013.00746

Vogt, J., deHouwer, J., Koster, E. H. W., vanDamme, S., and Crombez, G. (2008). Allocation of spatial attention to emotional stimuli depends upon arousal and not valence. Emotion 8, 880-885. doi: 10.1037/a0013981

Vossel, S., Geng, J. J., and Fink, G. R. (2014). Dorsal and ventral attention systems: distinct neural circuits but collaborative roles. Neuroscientist 20, 150-159. doi: 10.1177/1073858413494269

Wager, T. D., Davidson, M. L., Hughes, B. L., Lindquist, M. A., and Ochsner, K. N. (2008). Prefrontal-subcortical pathways mediating successful emotion regulation. Neuron 59, 1037-1050. doi: 10.1016/j.neuron.2008.09.006
Wager, T. D., Phan, K. L., Liberzon, I., and Taylor, S. F. (2003). Valence, gender, and lateralization of functional brain anatomy in emotion: a meta-analysis of findings from neuroimaging. Neuroimage 19, 513-531. doi: 10.1016/S10538119(03)00078-8

Wheeler, R. E., Davidson, R. J., and Tomarken, A. J. (1993). Frontal brain asymmetry and emotional reactivity: a biological substrate of affective style. Psychophysiology 30, 82-89. doi: 10.1111/j.1469-8986.1993.tb03207.x

Conflict of Interest Statement: The authors declare that the research was conducted in the absence of any commercial or financial relationships that could be construed as a potential conflict of interest.

Received: 14 Jan 2014; accepted: 05 May 2014; published online: 23 May 2014.

Citation: Grimshaw GM and Carmel D (2014) An asymmetric inhibition model of hemispheric differences in emotional processing. Front. Psychol. 5:489. doi: 10.3389/ fpsyg.2014.00489

This article was submitted to Cognition, a section of the journal Frontiers in Psychology. Copyright (๑) 2014 Grimshaw and Carmel. This is an open-access article distributed under the terms of the Creative Commons Attribution License (CC BY). The use, distribution or reproduction in other forums is permitted, provided the original author(s) or licensor are credited and that the original publication in this journal is cited, in accordance with accepted academic practice. No use, distribution or reproduction is permitted which does not comply with these terms. 